\title{
MENINGKATKAN KEMAMPUAN KOMUNIKASI MATEMATIK PADA MAHASISWA MELALUI PENDEKATAN CONTEXTUAL TEACHING AND LEARNING (CTL)
}

\author{
Oleh: \\ Anik Yuliani \\ Pendidikan Matematika, STKIP Siliwangi Bandung \\ anik_yuliani070886@yahoo.com
}

\begin{abstract}
ABSTRAK
Salah satu yang menjadi fokus utama pengembangan pembelajaran matematika dari sekolah dasar sampai dengan tingkat perguruan tinggi adalah kemampuan komunikasi matematik. Mata kuliah di prodi pendidikan matematika yang banyak melibatkan kemampuan komunikasi matematik mahasiwa adalah mata kuliah statistika penelitian pendidikan matematika. Salah satu pembelajaran yang sesuai dengan karakteristik mata kuliah statistika penelitian pendidikan matematika yaitu pembelajaran dengan menggunakan pendekatan Contextual Teaching and Learning (CTL). Adapun yang menjadi tujuan dari penelitian ini adalah untuk menelaah peningkatan kemampuan komunikasi matematik mahasiswa yang memperoleh pembelajaran dengan pendekatan Contextual Teaching and Learning (CTL) dengan mahasiswa yang memperoleh pembelajaran dengan cara biasa. Metode penelitian yang digunakan dalam penelitian ini adalah eksperimen dengan desain eksperimen kelompok kontrol postes only. Populasi dalam penelitian ini adalah seluruh mahasiswa jurusan pendidikan matematika STKIP Siliwangi Bandung. Kemudian diambil mahasiswa angkatan 2011 kelas A1 dan A2 sebagai subyek sampel. Kelas A2 sebagai kelas eksperimen dan kelas A1 sebagai kelas kontrol. Instrumen dalam penelitian ini adalah seperangkat soal tes komunikasi matematik. Berdasarkan penelitian yang dilakukan dan hasil analisis secara kuantitatif, diperoleh kesimpulan bahwa peningkatan kemampuan komunikasi matematik mahasiswa yang memperoleh pembelajaran dengan pendekatan Contextual Teaching and Learning (CTL) lebih baik daripada mahasiswa yang memperoleh pembelajaran dengan cara biasa pada taraf signifikansi $5 \%$.
\end{abstract}

Kata Kunci : Contextual Teaching and Learning, Komunikasi Matematis.

\begin{abstract}
One main goal of Mathematics learning development from primary to university level is the ability of mathematics communication. The subject that involves this in education mathematics major is the statistic of education mathematics study. The method that meets the caracter of this subject is CTL approach. The goal of this study is to analyze the improvement of mathematics comunication ability of the students who learn CTL approach and those who do not learn the approach. The applied method for this study is experimental control group postest only. The study population was all students of 2011 , class a1 and a2. Class a2 as the exsperimental group and a1 as control group. Instrument in this study is a set
\end{abstract}


of problem of mathematic communication. This results of this study and analyze data as quantitative is an increase in mathematics communication ability of students who abtain CTL approach better than the increase in mathematics communication ability of students receiving conventional learning.

Keywords: mathematics communication, CTL approach

\section{PENDAHULUAN}

Salah satu yang menjadi fokus utama pengembangan pembelajaran matematika dari sekolah dasar sampai dengan tingkat perguruan tinggi adalah kemampuan komunikasi matematik. Baroody (Ansari, 2003), mengemukakan bahwa terdapat dua alasan mengapa kemampuan komunikasi matematik sangat penting dimiliki oleh peserta didik. Alasan pertama, mathematics as language, yang diartikan bahwa matematika tidak hanya sekedar alat bantu dalam berpikir, alat untuk menemukan pola, menyelesaikan masalah atau mengambil kesimpulan, tetapi matematika juga $a$ valuable tool for communicating a variety of ideas clearly, precisely, and succinctly. Alasan kedua, mathematics learning as social activity, artinya sebagai aktivitas sosial dalam pembelajaran matematika, matematika juga sebagai wahana interaksi antar peserta didik dan juga komunikasi antara guru/dosen dan peserta didik. Hal ini merupakan bagian penting untuk nurturing children's mathematical potential.

Hal tersebut sejalan dengan tujuan pembelajaran matematika yang tertuang dalam National Council of Teachers of Mathematics (NCTM) yang menetapkan bahwa kemampuan matematik yang seharusnya dimiliki oleh peserta didik meliputi kemampuan pemecahan masalah, penalaran dan pembuktian, komunikasi, koneksi, dan representasi (Wahyudin, 2008).

Adapun yang menjadi karakteristik kemampuan komunikasi matematik menurut Sumarmo (2010) di antaranya adalah: (a) Menyatakan suatu situasi, gambar, diagram, atau benda nyata ke dalam bahasa, simbol, idea, atau model matematis; (b) Menjelaskan idea, situasi, dan relasi matematika secara lisan atau tulisan; (c) Mendengarkan, berdiskusi, dan menulis tentang matematika; (d) Membaca dengan pemahaman suatu representasi matematika tertulis; (e) Mengungkapkan kembali suatu uraian atau paragraf matematika dalam bahasa sendiri.

Salah satu mata kuliah di prodi pendidikan matematika yang banyak melibatkan kemampuan komunikasi matematik mahasiwa adalah mata kuliah statistika penelitian pendidikan matematika. Pada mata kuliah tersebut para mahasiswa dituntut untuk tidak hanya mampu menggunakan kemampuan penalaran saja, tetapi mereka juga dituntut untuk memiliki kemampuan komunikasi matematik yang baik. Dengan memiliki kemampuan komunikasi matematik yang baik para mahasiswa akan dapat memahami permasalahan-permasalahan yang berkaitan dengan statistika penelitian pendidikan matematika. Sebagai fasilitator, dosen harus dapat 
menentukan pendekatan pembelajaran yang tepat dan sesuai dengan karakteristik dari materi statistika penelitian pendidikan matematika. Peran dosen dalam menekankan kemampuan komunikasi matematik juga tidaklah mudah, karena membutuhkan keahlian untuk memunculkan ide-ide mahasiswa agar dapat menumbuhkan dan mengembangkan potensi yang dimiliki oleh para mahasiswa baik secara individu maupun secara berkelompok dengan rekannya.

Salah satu pembelajaran yang sesuai dengan karakteristik mata kuliah statistika penelitian pendidikan matematika yaitu pembelajaran dengan menggunakan pendekatan Contextual Teaching and Learning (CTL), di dalam pendekatan CTL masalah yang diangkat haruslah bersifat kontekstual, dan di dalamnya terdapat komunitas belajar yang menfasilitasi mahasiswa agar dapat mengungkapkan proses berpikir dan berargumentasi, sehingga kemampuan komunikasi matematik mahasiswa dapat lebih baik.

Salah satu cara untuk meningkatkan kemampuan komunikasi matematik yaitu dengan menciptakan suasana yang demokratis, yaitu individu dilatih untuk dapat mengemukakan pendapat kepada pihak lain melalui diskusi, kemudian dilatih untuk bisa berpikir mandiri dan diberikan suasana yang aman, nyaman dan menyenangkan sehingga individu tidak takut berbuat kesalahan dalam mengemukakan pendapatnya (Jossey, 2009). Dari pernyaataan tersebut, agar seorang mahasiswa memiliki kemampuan komunikasi matematik yang baik, maka dosen harus menyusun sebuah pembelajaran dengan suasana yang kaya akan interaksi baik mahasiswa dengan mahasiswa, atau pun mahasiswa dengan dosen melalui diskusi kelas. Berdasarkan uraian tersebut, pendekatan CTL sangat tepat untuk mengatasi rendahnya kemampuan komunikasi ini, karena dalam pembelajaran yang menggunakan pendekatan CTL, mahasiswa selalu diberikan permasalahan kontekstual yang realistik, kemudian adanya masyarakat belajar, penilaian selalu bersifat autentik dan pembelajaran dikemas menyenangkan.

Berdasarkan paparan di atas, maka peneliti tertarik untuk melakukan penelitian dengan judul "Meningkatkan Kemampuan Komunikasi Matematik pada Mahasiswa Melalui Pendekatan Contextual Teaching And Learning (CTL)".

Berdasarkan latar belakang masalah di atas, rumusan masalah dalam penelitian ini adalah sebagai berikut: Apakah peningkatan kemampuan komunikasi matematika mahasiswa yang memperoleh pembelajaran dengan pendekatan Contextual Teaching and Learning (CTL) lebih baik daripada mahasiswa yang memperoleh pembelajaran dengan cara biasa?

Dengan diadakannya penelitian ini, diharapkan dapat bermanfaat :

1. Bagi mahasiswa, penerapan pembelajaran dengan pendekatan Contextual Teaching and Learning (CTL) sebagai salah satu sarana untuk melibatkan aktivitas mahasiswa secara optimal dalam memahami konsep matematika 
sehingga konsep yang semula abstrak akan lebih cepat dipahami secara terintegrasi.

2. Bagi peneliti, merupakan pengalaman yang berharga sehingga dapat dijadikan bahan pertimbangan untuk mengembangkan kemampuan komunikasi matematik pada berbagai jenjang pendidikan.

\section{KEMAMPUAN KOMUNIKASI MATEMATIK, CONTEXTUAL TEACHING AND LEARNING (CTL)}

\section{Kemampuan Komunikasi Matematik}

Menurut Sudrajat (2001), mengemukakan bahwa kemampuan komunikasi matematik merupakan kemampuan yang dapat menyertakan dan memuat berbagai kesempatan untuk berkomunikasi dalam bentuk: (1) merefleksikan benda-benda nyata, gambar atau ide-ide matematika; (2) membuat model situasi atau persoalan menggunakan metode lisan, tertulis konkret, grafik, dan aljabar; (3) menggunakan keahlian membaca, menulis, dan menelaah untuk menginterpretasi dan mengevaluasi ide-ide, simbol, istilah serta informasi matematika; (4) merespon suatu pernyataan/ persoalan dalam bentuk argumen yang meyakinkan.

Sementara itu Sumarmo (2010) menjelaskan kegiatan yang tergolong pada komunikasi matematis di antaranya adalah: (a) Menyatakan suatu situasi, gambar, diagram, atau benda nyata ke dalam bahasa, simbol, idea, atau model matematis; (b) Menjelaskan idea, situasi, dan relasi matematika secara lisan atau tulisan; (c) Mendengarkan, berdiskusi, dan menulis tentang matematika; (d) Membaca dengan pemahaman suatu representasi matematika tertulis; (e) Mengungkapkan kembali suatu uraian atau paragraf matematika dalam bahasa sendiri. Cockroft (Shadiq, 2004) menyatakan pentingnya siswa belajar matematika dengan alasan bahwa matematika merupakan alat komunikasi yang sangat kuat dan berpengaruh (powerful), teliti dan tepat (concise), serta tidak membingungkan (unambiguous).

Melihat pentingnya kemampuan komunikasi untuk siswa, NCTM (Shadiq, 2004) mendeklarasikan pernyataan bahwa pembelajaran di kelas TK sampai SMU di Amerika Serikat haruslah memberikan kesempatan kepada siswa untuk: (a) Mengorganisasi dan mengkonsolidasikan pemikiran dan ide matematika dengan cara mengkomunikasikannya; (b) Mengkomunikasikan pemikiran matematika mereka secara logis dan jelas kepada teman sejawatnya, gurunya dan orang lain; (c) Menganalisis dan mengevaluasi pemikiran orang lain. Adapun indikator komunikasi matematis yang dimaksud dalam penelitian ini adalah komunikasi tertulis yang diukur dengan soal tes hasil belajaryang meliputi kemampuan menjelaskan suatu persoalan secara tertulis dalam bentuk gambar (Menggambar); kemampuan menyatakan suatu persoalan secara tertulis dalam bentuk model matematis (Ekspresi Matematis); serta kemampuan menjelaskan ide atau situasi dari suatu gambar yang diberikan dengan kata-kata sendiri dalam bentuk tulisan (Menulis). 


\section{Contextual Teaching and Learning}

Pendekatan kontekstual merupakan salah satu pendekatan pembelajaran matematika yang diduga sejalan dengan harapan dari kurikulum Indonesia saat ini. Pendekatan kontekstual memberikan arahan materi berdasarkan konteks-konteks yang ada dilingkungan kita sehari-hari yang sudah tidak asing bagi siswa, dengan demikian diharapkan siswa akan merasa senang untuk belajar matenatika. Hal ini sejalan dengan pengertian CTL yang dikemukakan oleh Howey, et al. (2001), bahwa pembelajaran kontekstual adalah pembelajaran yang memberikan kesempatan kepada para siswa dalam menerapkan pemahaman dan kemampuan akademiknya dalam konteks yang bervariasi, baik konteks itu di dalam atau di luar sekolah. Dengan adanya penyajian materi yang sifatnya kontekstual diharapkan siswa dapat menyelesaikan masalah-masalah dunia nyata atau fenomena-fenomena yang terkait.

Sementara itu Nurhadi (2003) menjelaskan bahwa pendekatan CTL merupakan salah satu konsep belajar yang sangat membantu guru dalam mengaitkan antara materi yang diajarkan dengan situasi dunia nyata, guru mendorong siswa membuat hubungan antara pengetahuan yang dimilikinya dengan penerapannya dalam kehidupan mereka sebagai anggota keluarga dan masyarakat. Sejalan dengan Nurhadi, Poedjiadi (2005), juga mengemukakan pendekatan CTL adalah suatu pendekatan pembelajaran yang mengaitkan antara materi yang diajarkan dengan situasi dunia nyata siswa dan mendorong siswa membuat hubungan antara pengetahuan yang dimilikinya dengan penerapannya dalam kehidupan mereka sebagai individu, anggota keluarga, anggota masyarakat dan bangsa. Dalam pembelajaran yang menggunakan CTL, siswa dilibatkan secara langsung dalam aktivitas penting yang membantu para siswa mengaitkan palajaran akademis dengan konteks kehidupan nyata yang mereka hadapi. Penemuan makna merupakan ciri utama dari CTL (Johnson dan Alwasilah, 2002).

Johnson dan Alwasilah (2002) mengatakan bahwa CTL adalah sistem yang menyeluruh yang terdiri atas bagian-bagian yang salin terhubung. Adapun sistem CTL mencakup 8 komponen yaitu :1). Membuat keterkaitan-keterkaitan yang bermakna; 2). Melakukan pekerjaan yang berarti; 3). Melakukan pembelajaran yang diatur sendiri; 4). Bekerja sama; 5). Berpikir kritis dan kreatif; 6). Membantu individu untuk tumbuh dan berkembang; 7). Mencapai standar yang tinggi; 8). Menggunakan penilaian autentik.

Dengan melalui ke delapan proses tersebut diharapkan siswa dapat mamahami pentingnya matematika sehingga siswa akan mendapatkan makna yang lebih dalam terhadap konteks yang dipelajarinya. Hal tersebut sejalan dengan pendapat Mulyasa (2005) bahwa pembelajaran konstektual mendorong siswa memahami hakekat, makna, dan manfaat belajar, sehingga memungkinkan mereka rajin dan termotivasi untuk senantiasa belajar, bahkan kecanduan belajar. Berdasarkan teori-teori tentang 
CTL yang telah dipaparkan di atas maka definisi CTL yang digunakan dalam penelitian ini adalah pendekatan CTL merupakan salah satu konsep belajar mengaitkan antara materi yang diajarkan dengan situasi dunia nyata yang mereka hadapi.

\section{METODE DAN PROSEDUR PENELITIAN}

Penelitian ini merupakan penelitian eksperimen dengan disain penelitiannya sebagai berikut :

$$
\begin{array}{lll}
O & X & O \\
O & & \text { (Ruseffendi, 2005) }
\end{array}
$$

Keterangan :

O : Tes Kemampuan komunikasi matematik

$\mathrm{X} \quad$ : Perlakuan dengan pendekatan Contextual Teaching and Learning

Populasi dalam penelitian ini adalah seluruh mahasiswa jurusan pendidikan matematika STKIP Siliwangi Bandung. Kemudian diambil mahasiswa angkatan 2011 kelas A1 dan A2 sebagai subyek sampel. Kelas A2 sebagai kelas eksperimen dan kelas A1 sebagai kelas kontrol. Disamping skenario pembelajaran untuk pendekatan Contextual Teaching and Learning (CTL), dalam penelitian ini digunakan Instrumen berupa tes kemampuan komunikasi matematik.

\section{Instrumen Penelitian}

Untuk memperoleh data dalam penelitian ini digunakan beberapa macam instrumen, yaitu seperangkat tes kemampuan komunikasi matematik. Untuk mengetahui seberapa besar peningkatan kemampuan komunikasi matematik mahasiswa sebelum dan setelah kegiatan pembelajaran, dilakukan analisis skor gain ternormalisasi yang dihitung dengan menggunakan rumus sebagai berikut:

$$
\mathrm{g}=\frac{\text { skor tes akhir }- \text { skor tes awal }}{\text { skor maksimum ideal -skor tes awal }}
$$

Tingkat perolehan skor gain ternormalisasi dikelompokkan kedalam tiga kategori, yaitu :

$$
\begin{aligned}
& 0,70<(\mathrm{g}) \quad \text { :Tinggi } \\
& 0,30 \leq(\mathrm{g}) \leq 0,70 \quad: \text { Sedang } \\
& (\mathrm{g})<0,30 \quad: \text { Rendah }
\end{aligned}
$$




\section{ANALISIS DATA DAN PEMBAHASAN}

\section{Statistik Deskriptif}

Berdasarkan pengolahan data skor pretes, postes dan gain terhadap aspek komunikasi matematis yang akan diukur, diperoleh skor rata-rata $(\bar{x})$ dan simpangan baku $(s)$. Berikut ini disajikan hasil pretes, postes dan gain kelompok mahasiswa yang mendapat pembelajaran dengan pendekatan CTL dan kelompok mahasiswa yang mendapat pembelajaran biasa.

Tabel 1

Rekapitulasi Hasil Pretes, Postes dan Gain Kemampuan Komunikasi Matematik

\begin{tabular}{|c|c|c|c|c|c|c|c|c|c|c|c|c|c|c|}
\hline \multirow{3}{*}{$\begin{array}{c}\text { Aspek } \\
\text { yang } \\
\text { diukur }\end{array}$} & \multicolumn{7}{|c|}{ CTL } & \multicolumn{7}{|c|}{ Biasa } \\
\hline & \multirow{2}{*}{$\mathbf{N}$} & \multicolumn{2}{|c|}{ Pretes } & \multicolumn{2}{|c|}{ Postes } & \multicolumn{2}{|c|}{ Gain } & \multirow{2}{*}{$\mathbf{N}$} & \multicolumn{2}{|c|}{ Pretes } & \multicolumn{2}{|c|}{ Postes } & \multicolumn{2}{|c|}{ Gain } \\
\hline & & $\bar{x}$ & $S$ & $\bar{x}$ & $s$ & $\bar{x}$ & $s$ & & $\bar{x}$ & $s$ & $\bar{x}$ & $s$ & $\bar{x}$ & $S$ \\
\hline $\begin{array}{c}\text { kom } \\
\text { mat }\end{array}$ & 53 & 4,79 & 1,32 & 12,92 & 1,53 & 0,53 & 0,11 & 59 & 4,42 & 1,35 & 10,32 & 1,53 & 0,37 & 0,13 \\
\hline
\end{tabular}

Keterangan : Skor Ideal Tes Kemampuan Komunikasi Matematik = 20

Berdasarkan Tabel 1, diketahui bahwa untuk aspek kemampuan komunikasi matematis, rata-rata skor pretes pada kelompok mahasiswa yang mendapat pembelajaran dengan pendekatan CTL tidak berbeda jauh dengan kelompok mahasiswa yang mendapat pembelajaran biasa. Sedangkan pada rata-rata skor postes kelompok mahasiswa yang mendapat pembelajaran dengan pendekatan CTL lebih besar dari pada yang mendapat pembelajaran biasa. Untuk rata-rata gain pada kelompok mahasiswa yang mendapat pembelajaran dengan pendekatan CTL juga terlihat lebih besar dari pada kelompok mahasiswa yang mendapat pembelajaran biasa.

Untuk mendukung deskripsi peningkatan kemampuan komunikasi matematik yang telah dijelaskan, maka dilakukan analisis data kemampuan komunikasi matematik mahasiswa melalui uji statistik dengan menggunakan uji perbedaan dua rata-rata.

\section{Analisis data gain}

\section{a. Uji Normalitas}

$\mathrm{H}_{0}$ : sampel berasal dari populasi berdistribusi normal

$\mathrm{H}_{1}$ : sampel berasal dari populasi tidak berdistribusi normal

Kriteria pengujian, jika sig. $>\alpha$ maka $\mathrm{H}_{0}$ diterima. Setelah dianalisis dengan menggunakan SPSS 17 diperoleh hasil pada Tabel 2. 
Tabel 2

Uji Normalitas Gain Kemampuan Komunikasi Matematik

\begin{tabular}{|ll|r|r|r|}
\hline \multirow{2}{*}{} & kelas & \multicolumn{3}{|c|}{ Kolmogorov-Smirnov } \\
\cline { 2 - 5 } & & Statistic & \multicolumn{1}{c|}{ df } & \multicolumn{1}{c|}{ Sig. } \\
\hline gain & pendekatan CTL & .136 & 53 & .016 \\
komunikasi & $\begin{array}{l}\text { pendekatan } \\
\text { biasa }\end{array}$ & .134 & 59 & .011 \\
\hline
\end{tabular}

a. Lilliefors Significance Correction

Dengan memperhatikan kriteria pengujian di atas, ternyata nilai signifikansi kelas eksperimen 0,016 dan pada kelas kontrol 0,011, keduanya lebih kecil dari $\alpha=0,05$. Artinya pada taraf signifikansi 5\% data gain kemampuan komunikasi matematik mahasiswa yang memperoleh pembelajaran dengan pendekatan CTL dan pembelajaran biasa tidak berdistribusi normal.

Karena kedua data tersebut tidak berdistribusi normal, maka untuk menguji perbedaan dua rata-rata dilanjutkan dengan uji Mann-Whitney.

\section{b. Uji Mann-Whitney}

$$
\begin{aligned}
& \mathrm{H}_{0}: \mu_{1}=\mu_{2} \\
& \mathrm{H}_{\mathrm{A}}: \mu_{1}>\mu_{2}
\end{aligned}
$$

Kriteria pengujian : Jika sig $>0,05$ maka $\mathrm{H}_{0}$ diterima

Tabel 3

Uji Perbedaan Dua Rata-Rata Gain Kemampuan Komunikasi Matematik

\begin{tabular}{|lll|r|}
\hline & & \multicolumn{1}{c|}{$\begin{array}{c}\text { gain } \\
\text { komunikasi }\end{array}$} \\
\hline Mann-Whitney U & & 501.500 \\
Wilcoxon W & & & 2271.500 \\
Z & & & -6.199 \\
Asymp. Sig. (2-tailed) & & & .000 \\
Monte Carlo Sig. (2-tailed) & Sig. & Lower Bound & $.000^{\mathrm{a}}$ \\
& $95 \%$ Confidence Interval & .000 \\
& & Upper Bound & .026 \\
Monte Carlo Sig. (1-tailed) & Sig. & & $.000^{\mathrm{a}}$ \\
& $95 \%$ Confidence Interval & Lower Bound & .000 \\
& & Upper Bound & .026 \\
\hline
\end{tabular}

a. Based on 112 sampled tables with starting seed 299883525.

b. Grouping Variable: kelas 
Dari Tabel 3 diperoleh nilai sig $(1$-tailed $)=0,000$; atau dengan kata lain sig $<0,05$. Hal tersebut dapat disimpulkan bahwa peningkatan kemampuan komunikasi matematik mahasiswa yang memperoleh pembelajaran dengan pendekatan Contextual Teaching and Learning (CTL) lebih baik daripada siswa yang memperoleh pembelajaran dengan cara biasa pada taraf signifikansi $5 \%$.

\section{KESIMPULAN}

Berdasarkan analisis data diperoleh kesimpulan peningkatan kemampuan komunikasi matematik mahasiswa yang memperoleh pembelajaran dengan pendekatan Contextual Teaching and Learning (CTL) lebih baik daripada siswa yang memperoleh pembelajaran dengan cara biasa pada taraf signifikansi $5 \%$.

\section{DAFTAR PUSTAKA}

Ansari, B.I. (2003). Menumbuhkembangkan Kemampuan Pemahaman dan Komunikasi Matematik Siswa SMU melalui Strategi Think-TalkWrite.Disertasi pada PPS UPI Bandung: tidak diterbitkan.

Howey, K. R. (2001). "Introduction to the Commissioned Paper", dalam Howey, et al. Contextual Teaching and Learning: Preparing Teacher to Enhance Student Success in the Workplace and Beyond (pp. 19-31). Eric Clearing House Teaching and Teacher Education.

Johnson, E.B dan Alwasilah. C. (2002). Contextual Teaching and Learning. Jakarta: MLC.

Jossey-Bass Teacher (2009). Mega-Fun Math Games and Puzzles for the Elementary Grades. USA: John Wiley \& Sons, Inc.

Mulyasa, E. (2005), Menjadi Guru Profesional, Bandung, Ramaja Rosda Karya

Nurhadi (2003), Pendekatan Konstektual (Contextual Teaching and Learning), Jakarta, Ditjen Dikdasmen Depdiknas.

Poedjiadi, A. (2005), Sain Teknologi Masyarakat, Model pembelajaran Kontekstual Bermuatan Nilai, Bandung, Remaja Rosdakarya.

Ruseffendi, E. T. (2005). Dasar-Dasar Penelitian Pendidikan dan Bidang NonEksakta Lainnya. Bandung : Tarsito

Shadiq, F. (2004). Penalaran, Pemecahan Masalah dan Komunikasi Matematika. Diklat Instruktur PengembanganMatematika SMP Jenjang Dasar. PPPG Matematika. Yogyakarta.

Sumarmo, U. (2010). Berfikir dan Disposisi Matematik: Apa, Mengapa, dan Bagaimana Dikembangkan pada Peserta Didik. FPMIPA UPI.Tersedia.

Wahyudin (2008). Pembelajaran dan Model-model Pembelajaran. Bandung: UPI. 